\title{
Los migrantes: signos de una nueva era. Entrevista al Padre Solalinde.
}

Diego Contreras-Medrano, University of Oregon

Diegoc@uoregon.edu

Pedro García-Caro, University of Oregon

pgcaro@uoregon.edu

\section{Resumen}

Esta entrevista acerca de las políticas migratorias de EEUU y México y las estrategias de resistencia que se han creado en los últimos años para huir de la represión a los migrantes, se llevó a cabo en el contexto de la visita del Padre Solalinde a la Universidad de Oregón en mayo de 2018. Importante para el contexto es también la campaña presidencial de Andrés Manuel López Obrador que resultaría victorioso en julio y cuyo sexenio dio comienzo en diciembre de ese mismo año.

Palabras clave: Migración mexicana, política mexicana, AMLO, campo de refugiados, carteles de droga 


\section{$\Delta$ lejandro Solalinde Guerra (México, 1945) es un sacerdote católico}

mexicano que continúa una larga tradición de religiosos disconformes con el orden social, rebeldes contra la injusticia. Solalinde vino a la Universidad de Oregón en mayo de 2018 para ofrecer la "Conferencia Anual Padre Las Casas sobre Derechos Humanos" bajo los auspicios del Programa de Estudios Latinoamericanos de la UO, las organizaciones MeCha, “Adelante Sí”, el Instituto Migrante Guanajuatense, Oak Hill School, y la Oficina de la Vicepresidenta para la Equidad y la Inclusión, Yvette Alex Assensoh. Durante los seis días que estuvo en Eugene, sus apariciones se multiplicaron: estuvo en la radio pública local, invitado al programa “Ahora Sí” de Armando Morales (KLCC 89.7) para una entrevista bilingüe, se reunió con clases de Estudios Latinoamericanos, con el grupo de estudiantes de MeCha de la UO, y con representantes de MORENA en Oregón.

Sus formas son directas, su análisis también. Solalinde es un defensor de los derechos humanos con una voz y una acción inconfundibles a lo largo de las últimas dos décadas. En sus escritos, en sus homilías, en sus numerosas apariciones en los medios públicos, el mensaje de Solalinde es fácilmente comprensible: dignidad y trato humano para todos, transgrediendo las fronteras trazadas en la piel, entre etnicidades, entre nacionalidades, creencias, y clases. Fundador en julio de 2007 del albergue "Hermanos en el camino", en ciudad Ixtepec (Oaxaca), Solalinde ha creado una red de refugio, seguimiento, y apoyo a los migrantes que atraviesan el territorio mexicano con destino a EEUU. Solalinde lucha por despertar una conciencia de la crisis humanitaria y la pasividad de todos los estados y agentes involucrados. Las dimensiones y la función de su albergue se asemejan a las de un campo de refugiados: un espacio de acogida que ha llegado a tener a más de mil personas en distintos momentos, y que el Padre Solalinde ha llegado a defender poniendo su vida en peligro, como revela en esta entrevista. Sus públicos desafíos a la jerarquía católica en México y su denuncia de las autoridades locales y nacionales 
demuestran que la labor de Solalinde es efectiva: Solalinde se ha convertido en portavoz público de cientos de miles de seres humanos que no tienen acceso a una vida digna y que son tratados como verdaderos rebaños humanos en un contexto de violencias impunes, de ausencia de políticas públicas humanitarias efectivas, y tráficos masivos de personas y de estupefacientes, a menudo coordinados por criminales organizados y agentes estatales fuera de todo control. Solalinde visualiza la migración hacia el norte como una señal del colapso del estado moderno en amplias partes de Centroamérica y de México: los migrantes son actores de cambio que marcan el final de una era y el comienzo de otra. Pese a las dificultades, las prohibiciones, la violencia, los muros y fronteras, la gente marcha ocupando el espacio, huyendo de violencias cotidianas sin nombre, buscando nuevas oportunidades para una vida mejor. Pero antes que nada, marcha transformando el miedo en coraje, demandando dignidad y un completo reconocimiento de su derecho humano a una vida completa y en paz.

En la entrevista, Solalinde evoca "El sueño imposible" [The Impossible Dream], un tema de Man of La Mancha, la versión de Don Quijote estrenada en 1965 en Broadway, una canción que celebra la lucha por llegar a una estrella inalcanzable, y que imagina una marcha a través del infierno para hacer realidad nobles ideales: "To be willing to march / March into hell / For that heavenly cause [...]". La nueva era que según Solalinde inauguran estos migrantes y refugiados es un ideal noble, un futuro de reconocimiento de injusticias y de reparaciones, del triunfo de la humanidad sobre los mercaderes de cuerpos y cosas, una nueva era que está siempre a la vuelta de la esquina.

García-Caro: Ayer estuvimos hablando del libro de "Los migrantes del Sur", su libro que salió en diciembre de 2017 y del momento en el que [usted] decide construir el albergue. También hoy en el almuerzo hemos estado hablando 
de la pelea con el obispo local acerca del albergue, la propiedad del albergue y a quién le pertenece. Me gustaría pensar en la posible expansión de la Red de albergues. Me parece una imagen muy potente, que la Red de albergues se convierta casi en una especie de alternativa directa que rompe con el muro. Es como una línea perpendicular al muro, y que supone en término simbólicos el quiebre del modelo de control... [Solalinde pide que paremos la grabación brevemente].

Solalinde:

El planteamiento primero quizá sería el significado de la migración. La emigración... si tú quieres, tiene aspectos manejables, aspectos asibles, tangibles, medibles, cuantificables, que tú puedes verlos como un fenómeno, como hacen los científicos sociales. Pero hay una parte intangible, hay una parte que no corresponde a los parámetros de los que no estamos acostumbrados a ver los hechos.

Yo le decía, en historia un acontecimiento es un hecho relevante y yo estoy seguro, yo así lo calificaría, el paso de los migrantes. La migración actual es el hecho más relevante. Es el signo más importante de una gestación de una nueva era. Primero, cuando un migrante, estoy hablando de migrantes, 247 millones de personas en movimiento, en situación de movilidad humana en el mundo -me refiero a África, pero también a América, por decir algo, pero no son las únicas migraciones- algo que tú te debes preguntar, “¿por qué tuvieron que salir?", porque no son migraciones emprendedoras. No 
son migraciones de conquista. Son migraciones forzadas. Entonces tú te tienes que plantear por qué en los lugares de origen ya no hay condiciones de vida mínimas. ¿Por qué la gente tiene que emigrar forzosamente? Porque ya no se puede vivir. Entonces esa pregunta en sí, abre las posibilidades de una investigación que te va a llevar a una caducidad sistémica. El sistema capitalista ha provocado eso porque ya no garantiza la vida de las personas. Pero aquí también caduca no solamente el capitalismo, también acaba de caducar la modernidad, el estado moderno porque ya no garantiza... El estado moderno sucumbió ante el poder fáctico capitalista y ya. Ese estado de la modernidad, ya se quedó atrás para dar paso en la posmodernidad, a un estado administrador, un estado que administra los intereses de la oligarquía capitalista del mundo.

García-Caro: $\quad$ Por eso mismo le preguntaba -yo sé que usted no quiere darse protagonismo- pero le preguntaba cómo la red de albergues que usted ha ayudado a crear es una respuesta perpendicular y que cuestiona y resiste radicalmente el muro...

Solalinde:

Si me permites, yo podría aterrizar en estas cuestiones coyunturales, pero quisiera platicar un poquito más sobre el marco general. Porque esto que me preguntas son ciertamente coyunturales, importantes, que hay que responderlas, porque son una respuesta sistémica, a una agresión sistémica también. De atropello a los 
derechos humanos.

Nada más quiero decirles que el migrante anuncia, en pocas palabras, que algo ya tronó, algo ya se acabó, ya no funciona. Entonces ellos empiezan la búsqueda de una nueva vida. Esa nueva vida pueden Ilamarla una nueva época, una nueva era. Pueden Ilamarle como ustedes quieran, pero es algo que todavía no conocemos, es algo que todavía no sabemos qué vaya pasar. Pero que está en marcha, sí. Que esté en proceso, sí. Ahora, otro tema es el tratamiento, las vicisitudes que sufre la migración en tránsito, tanto de África hacia Europa en el Mediterráneo, como del Sur a Estados Unidos por México. El equivalente al mar Mediterráneo -el peligro, el riesgo- es México. México, como país de tránsito, es peligrosísimo y tantos muertos o equivalentes, no sé, han cobrado el Mediterráneo, como el paso por México. Entonces conociendo esto, sabiendo esto, ya podemos entender que tenemos como acontecimiento una lucha sistémica entre dos polos: uno, el sistema capitalista, representado por Donald Trump, que no quiere a los migrantes, que es una resistencia contra los migrantes. Por otro lado, también están los migrantes que tienen vida propia, que no se asustan con Trump y que tampoco se inhiben con las legislaciones más racistas y más antiinmigrante que te puedes imaginar.

Tenemos los dos bloques que se están enfrentando. Yo no quiero llamarlo enfrentamiento porque no es enfrentamiento. De parte de los supremacistas, sí. De parte de los capitalistas, sí. De parte de los agentes del 
estado al servicio de los poderes fácticos capitalistas, sí. Es una agresión. Pero por parte de los migrantes, no. No es una guerra, es una resistencia. Es un poder muy grande, de caminar y de avanzar; donde tienen que avanzar contra todos los riesgos, contra todas las amenazas. Como si tuvieran un chip que nadie puede detener. Eso es lo que yo veo.

Ahora sí, podemos hablar. En el sur me tocó como misionero, sacerdote que además sí se da cuenta de todas estas cosas de las estructuras capitalistas y de todo esto, por el conocimiento que tengo, de haber tenido la oportunidad de haber estado en muchos lugares y confirmar eso. En la Unión americana, en 2013 me sirvió muchísimo visitar veintises estados de la Unión americana con motivos de una caravana que tuvimos de migrantes. Entonces entre preparación y la ejecución de la caravana, sí visitamos veintises estados. Me impresionó mucho conocer un poco más las entrañas de EEUU en relación, precisamente, con la migración. Siempre teniendo como eje transversal que lo va tocando todo. Y estuve en el Congreso y estuve oyendo a congresistas cómo hablaban de la migración, si se hacía o no se hacía la reforma migratoria. A Nancy Pelosi la escuché, y todo lo que decían me impresionó.

Entonces, todo eso que viví me ha ayudado para que, en el sur, que es donde me tocó estar, empezó a gestarse un cambio como respuesta. Cuando yo llego, yo no sabía qué pasaba. Lo que estaba sucediendo y lo que iba a suceder más adelante con los migrantes, ni 
siquiera lo imaginábamos. Estaba todo como oculto, no se visibilizaba. Hubo un momento en el que tuve que tomar la decisión, porque estaba amenazado de muerte. Y yo dije, “¿qué hago? Si me callo, tengo que huir, tengo que salir y dejar las cosas como están. O quedarme y aunque me arriesgue, pero cumplir con el acompañamiento que como sacerdote, como misionero tengo que dar con las personas migrantes".

A seis jesuitas, los amenazaron de muerte con armas. Los zetas. Entonces ellos entendieron y se fueron, pero me dijeron: "tienes dos caminos. Uno, que pidas ayuda al centro Miguel Agustín Pro, de los Jesuitas en México y que empiecen a ver cómo van a tratar este asunto; o que te vayas, que te salgas que te van a matar". Un padre, un compañero mío me lo dijo: "no hables como estás hablando porque te van a matar". Ahí me amenazaron y me tuve que callar. Yo me quedé pensando, y no me dio tiempo ni siquiera de decidir. Era necesario hacerlo. Tenía dos caminos, o llamar a la presa de plano y empezar a publicar todo eso. Y opté por llamar a la prensa, darlo a conocer y hacer todo el escándalo posible para que se dieran cuenta de lo que estaba pasando.

A partir ese momento, se empezó visualizar todo lo que estaba pasando, quiénes eran los que estaban amenazando a los migrantes, qué querían hacer con ellos, qué proyectos de negocios masivos tenían que hacer con ellos en cuanto a secuestros, a todo esto. Y claro, vinieron años terribles: 2007, 2008, 2009, 2010, hasta el 2012 todavía fue muy fuerte. De 2012 en 
adelante, fueron amenazas, atentados esporádicos. Pero ya no fue esa tensión constante, como que ellos fueron perdiendo terreno. Un punto clave fue cuando en 2010, hace un secuestro de 50 migrantes, otra vez vuelvo quedarme en la opción. Eran 50 migrantes que habían secuestrado, yo tengo 21 testigos y el gobierno de Oaxaca y el gobierno federal me dicen, "si el padre Solalinde no pone una denuncia penal contra los que estaban haciendo eso, o sea los zetas, no podemos hacer nada". Así de fácil, fíjate. "Si no lo pone, no podemos hacer nada". Y yo dije, "voy, otra vez, a estar en la misma situación. Si no denuncio, pues me tengo que ir y ya. Pero si denuncio, me tengo que quedar y yo no voy a vivir dos días aquí; no me van a dejar vivir", decía, "me van a matar". Y tuve que tomar la decisión. Ese 22 de diciembre, de ese año, tomé la decisión, y puse cuatro demandas contra los Zetas. 2010.

García-Caro: 2012 es cuando se tuvo que marchar de Oaxaca.

Solalinde:

La situación se fue empeorando. Entonces, yo las puse el 22. El día 23, yo experimente una situación que he calificado de "pre-muerte" porque no sé cómo llamarle de otra manera. Yo estaba seguro que iba morir segurísimo que iba a morir. Eso el 22. El 22 yo dije, "no voy amanecer una..."

García-Caro: $\quad$...crónica de una muerte anunciada, como la novela de García Márquez... 
Solalinde: ...yo así lo sentía, así lo sentía. Y amanezco el día 23 y yo dije, "¿vale la pena vivir así con miedo? No. ¿Y los migrantes?" Estaba así [completamente lleno] el albergue. La primera vez que yo recuerdo, la primera vez que íbamos a disfrutar la nochebuena, porque nunca habíamos tenido la oportunidad de tener una nochebuena, nunca. Yo llamé a todos y le dije, "miren, estamos realmente amenazados. Estamos realmente amenazados de muerte, pero no vale la pena que estemos viviendo escondiéndonos, y viviendo con miedo. No vale la pena y vamos a olvidarnos de todo. Si nos matan nos matan, pero esta navidad, la vamos a celebrar bien y vamos a estar alegres y vamos a poner música y vamos a poner adornos, y vamos a hacer una cena muy buena". Y así lo hicimos. Y pasó esa navidad como la primera y la única que habíamos tenido en ese momento. Después me dejaron vivir y seguí viviendo. ¿A qué se debe eso? A que yo creo que se visibilizó tanto la cuestión de los migrantes, todo lo que querían hacer con ellos, para hacer secuestros grandes y masivos que se les calentó la plaza. Se les calentó la plaza y ya no pudieron con tantos medios, ya no pudieron hacer nada, porque todos los reflectores estaban puestos en ellos. Optaron mejor por no mover más problemas y se retiraron a Veracruz. Y luego de Veracruz al norte. Y luego en el norte decidieron que para qué estar peleando tanto conmigo en el sur, si allá en el norte podían esperarlos tranquilamente y secuestrarlos allá. Entonces ya no hicieron nada, se esperaron a que llegaran solitos. 
García-Caro:

Aquí hay un argumento o una lógica que es relativamente difícil de entender fuera de México; la de un grupo paramilitar que se sale del gobierno, los Zetas, que se dedica a secuestrar y asesinar en masa a cientos, posiblemente, o miles, de ciudadanos mexicanos, pero también centroamericanos. Es difícil entender la finalidad. Es decir, que les roben es una cosa, incluso que puedan comerciar, se puede especular.... Pero ha habido gente que se ha metido a investigar cuáles son las motivaciones de los Zetas para llevar a cabo esta violencia...

Solalinde:

Los Zetas no eran así, como fueron después. Yo creo que ellos, a pesar de todo, eran gente con educación. Todos católicos, todos con una educación de élite, del ejército. Pero les pasó algo. Felipe Calderón empieza a hacer su guerra absurda contra el narcotráfico y entonces de alguna manera los golpea y por un momento los descapitaliza, y ellos no pueden estar recibiendo la droga a crédito. Esas cosas no se hacen, se pagan inmediatamente. Porque no sabes si a los 5 minutos te van a matar a ti o van a matar al otro. Ellos no tenían dinero, entonces descubrieron, vieron porque era su ruta desde Chiapas, desde Tenosique; tanto por Tapachula como por Tenosique, descubren el flujo migratorio. En 2006, Felipe Calderón, en diciembre, hace un operativo en la frontera sur. En ese operativo de la frontera sur, no hacen nada de nada contra nadie, pero provoca una contención del flujo migratorio. Se retrasó el flujo 
migratorio por meses, Cuando ya retiró todo porque no iba a hacer nada, la gente empezó a pasar por grupos de 800 , por grupos de 100 en cada tren. Dos mil porque una vez llegaron dos mil en un mismo tren, y en el albergue llegaron 1200 personas porque es la cifra máxima que ha entrado juntos, todos a la vez. 1200 personas.

García-Caro: ¿Cuál es la capacidad del albergue?

Solalinde:

El albergue puede tener una capacidad muy poca, pero tiene mucho terreno, tienen 16,000 metros cuadrados. En un momento dado, puede hospedar a la gente en el piso o donde sea, caben miles. Como un campo de refugiados.

Cuando llegan ellos y empiezan a pasar, los Zetas empiezan a descubrir cosas; empiezan a experimentar. Primero, extorsionarlos. Pero no era suficiente, los Zetas no eran tan corrientes -por decirlo así- para conformarse con extorsionarlos, si no son asaltantes. Ellos van en grande. Entonces empezaron a descubrir cómo... los migrantes son pobres. Los migrantes del sur no tienen dinero, pero empezaron a pensar, a ver: "Ellos no, ¿pero a dónde van? A EEUU. Ahí tienen algún conocido, o familiar. Aquí no hay dólares, pero allá sí hay dólares". Pensaron que podían sacarles el dinero a los familiares, y no sabían si los familiares iban a responder o no. Y empezaron a hacer las pruebas, a mi me tocó cuando empezaron a hacer esto, los familiares empezaron a llamarme a mi, directamente a mi. "Padre, me están 
pidiendo dinero porque dicen que están secuestrados". Y dije, "pues déjenme ver", porque yo no sabía nada, a penas empezaba esto. Cuando ya me di cuenta, descubrieron ellos que los familiares sí podían pagar, y que la vida de un pariente, que la vida de un pobre vale mucho para ellos que sí estaban dispuestos a pagar. No sabían ni cuánto iban a cobrar, empezaron a probar cuánto era lo que podían pagar, hasta que Ilegaron más o menos a una cuota que era de 1,000 hasta 3,000 dólares por persona. Y los empezaron a pagar.

Después hicieron técnicas, las técnicas de convencimiento. Se llevaron gente a un lugar donde había una señal de celular, y luego llamaban a un familiar y se los sacaban. Los que eran por la buena, no los golpeaban, sobre todo los guatemaltecos, ellos no pelean, no se resisten. Ellos pagan porque tienen redes sociales muy importantes, son indígenas la mayor parte. Ellos pagan, no los maltratan; casi no los secuestran a ellos, pagan de antemano y ya no los secuestran y pasan. Porque la ganancia no le genera problemas al narcotráfico. Así le hicieron y se dieron cuenta de que los pobres valen. Los que no podían pagar en un principio, los dejaban ir. Pero como luego regresaban con nosotros, nosotros formábamos testimonio, poníamos la denuncia y empezamos a cuantificar, cuántos los secuestraban. Y pudimos darnos cuenta por investigaciones que secuestraban a 10,000 migrantes cada semestre. Cada seis meses, con una ganancia de veinticinco millones de dólares. Cada seis meses. De los que nos dábamos 
cuenta. Obviamente era muchísimo más, pero no era posible registrar eso, más de 10,000 migrantes.

Ellos se dan cuenta de que, si ellos dejan personas vivas, van a hablar, y entonces no quieren que hablen y empiezan a matarlos. Empezaron a llenar pozos, los llenan de cuerpos. Empezaron a llevar a los lagartos porque en la zona donde ellos estaban llevando a cabo los secuestros, había lagos con lagartos y los lagartos se los comían- luego empezaron a llenar cuevas, en Veracruz. Finalmente inventaron la técnica: un Zeta que se llamó -porque yo creo que ya lo han de haber matado- el Borrego, inventó esta técnica de los tambos de 200 litros. Se necesitaban varias personas: se necesita primero un sicario, un sicario que se encargaba de matarlos nada más. Luego el carnicero, se encargaba de destazarlos para que cupieron los cuerpos en tambos de 200 litros. Y luego el otro era el cocinero o el pozolero, para cocinarlos. Ya tenía experiencia de cómo hacerlo para no dejar más que restos calcinados. Pero aún así, todavía había otro más que en los últimos años hemos estado descubriendo. El último era recoger el resto de los tambos y luego irlos a tirar, pero no en la misma fosa, sino en diferentes fosas para que costara todavía más trabajo, si hubiera algún resto con ADN, pues no habría manera de cómo hacerlos. Como sucede en Colinas de Santa Fe, en Veracruz. Solecito descubrió eso, que sus familiares fueron encontrando restos de un familiar, pero les llamó la atención que sólo había uno o dos, pero los demás no estaban. Al principio pensaban que los demás 
se habían calcinado, pero después encontraron un resto de la misma persona en otra fosa. O sea, el crimen perfecto.

Ese día cuando pensamos que me iban a matar, pues dijimos, "nos la jugamos" sin saber si de veras me iban a matar o no. Pero yo estaba seguro de una cosa, no me podía quedar callado, ni tampoco podía dejar de poner una denuncia, cuando se debía de poner. Pero después no me mataron. Varias veces, los Zetas intentaron matarme, varias veces. Pero yo sigo pensando, hay algo que yo no entiendo: por lo menos una vez, en febrero de 2008, un Zeta llamado el Reinosa dijo que esa misma noche él iba a entrar a matarme con sus propias manos, fueron sus palabras. "Con mis propias manos". Esa misma noche, entró, pero no a matarme. Entró e hizo una especie de rito. Yo me dormía en una camioneta "tracker" porque no había dónde dormir, y dejaba la ventanilla abierta porque hacía mucho calor, pero cerca de la capilla porque ahí se dormían los migrantes. Yo los estaba cuidando, los estaba vigilando que no les pasara nada. Y esa noche yo me quedé dormido y entró el Reinosa. Con pistola en mano, metió la mano y me hizo así arriba de mi cabeza y se salió, pero no hizo nada. Un cocinero que se quedaba a dormir ahí, lo vio porque en ese momento había cerca del albergue, una torre con un foco muy fuerte, prácticamente se iluminaba todo el patio del albergue, aunque no tuviéramos luz. Yo pregunté a ese mucho en la mañana siguiente, me dijo "padre, entró una persona", y ya me describió todo 
como había pasado. ¿Y le dije, "estás seguro? ¿Cómo era?". Ya me lo describió: era güero, rubio, ojos claros, chaparrito, delgado. Yo lo conocía bien. Entró, pero no me hizo nada, pero me llamó la atención. Pasaron dos años. A los dos años yo me quedé siempre con la curiosidad de por qué no me habían matado: tenía el arma, había dicho que me iba a matar con sus propias manos, entró él, no había ninguna defensa ni ninguna resistencia. Me hubiera pegado unos dos balazos ahí y ya, ahí me quedaba.

Dos años después, un joven que antes era pollero -trabajaba como guía, era su trabajo, era un trabajo, como cualquiera, pero no abusaba de las personas, no les cobraba más, les cobraba la mitad, y la otra mitad lo recibía en el domicilio en EEUU, lo entregaba a su familia, sin ninguna queja de haber abusado con las mujeres, ni nada. Este muchacho se Ilamaba Juan Carlos, era creo que de Salamanca. Él llegaba conmigo, yo lo veía como cualquier persona con un trabajo, yo lo veía entonces como un tráfico de personas. Pero sucede que un día los Zetas lo obligaron a trabajar para ellos. Todos los coyotes así, los obligaron a trabajar para ellos, y los amenazaron de muerte. Pero se dio cuenta de que los entregaba para el secuestro, o para todo. Él era un hombre de conciencia, no le gustó eso y empezó a sentirse mal y mal. Un día le pasó algo que le sucedió a él, él supo que lo iban a matar. Y dijo, "pues si me van a matar, pues que sea con provecho y voy a hablar". Y habló y pidió hablar con una persona de gobernación y yo hablé con 
la persona de gobernación, y oí todo su testimonio, yo lo grabé. Le dijo el agente de gobernación, "oye, alguna vez han amenazado de muerte al Padre, ¿los Zetas? Sí”. Y él describió esa vez. Dice que cuando Reinosa me iba a matar, ese día le habló por teléfono a su jefe. Su jefe se llama o se llamaba Adrián, en Piedras Negras. Hay dos Adrianes: el hijo, que estaba afuera. Y otro el papá Zeta, que estaba adentro de la cárcel. Y el papá desde ahí movía todo, movía 150 polleros. Y él habló y le dijo, "oye, te hablé nada más para confirmarte la ejecución del cura”. Juan Carlos, que le decían el Chacal, estaba ahí, y cuando él oyó, el sabía de lo que estaba hablando porque era mi amigo, pero no dijo nada, se quedó callado nada más. Le dijo a Adrián, "haz tu trabajo y por ahora deja al cura". Esa fue la respuesta que le dio. "Haz tu trabajo y por ahora deja al cura”. Por eso es que él entró y no hizo nada, pero yo creo que ellos tienen como un rito, que, si ya había dicho algo, porque entró de todos modos al albergue, me tuvo pero no me mató. Esa fue la primera vez que yo me interrogo, ¿por qué no me mató? porque Adrián no me conocía. Es posible que Juan Carlos haya hablado con él y le haya dicho, "no mira, este cura no se mete con nosotros, él nos deja actuar", no sé que le haya dicho.

Luego hubo otras veces en que me hubieran matado, pero no me mataron. Yo muchas veces me he preguntado por qué si yo fui el que más persiguió a los Zetas, el que más les impidió, el que les metió denuncias penales. ¿Por qué no me mataron? Yo quiero creer que tal vez hubo 
alguien en esa organización que fue como mi protector. Yo creo, porque pasando el tiempo, en 2013 cuando yo hice la caravana de migrantes para acá, en Tennessee, se acercó gente del cártel del golfo. Allá me pudieron haber contactado cuando querían. Y me dijo, "mira, yo vengo del cártel del golfo y mi jefe te manda a saludar y te manda decir que, en primer lugar, a ti te respeta mucho porque tienes muchos pantalones. $Y$ él respeta mucho a los valientes y contigo no se mete. $Y$ te quiero decir que vamos a empezar a cobrar derecho de piso, que vamos a cobrar 1200 por cada migrante, de frontera a frontera. Pero queremos decirte que no les vamos a hacer nada. Los que no puedan pagar, se van a regresar hasta que puedan pagar". ¿Y le dije, "me aseguras que no les van a hacer nada?". "Sí -me dijo- no les vamos a hacer nada. Pero eso sí, no te vamos a toda nunca por las razones que te dije, pero si tú enfrentas nuestro negocio de narcotráfico, ahí sí eres hombre muerto". Le dije, "a mi no me interesa eso. Yo no soy policía. Yo soy pastor, me interesan los migrantes no la droga, eso es otra cosa". Como al mes y medio de que había sucedido eso, voy a Reinosa y fui a la bendición de una Casa del Migrante. Tuvimos una pequeña conferencia de prensa, y cuando acabó la conferencia, se acercaron dos personas, muy fornidas, de rojo. Yo pensé que eran periodistas mis escoltas estaban, yo tenía ya como dos o tres años con ellos- y estaban a dos o tres metros de donde yo estaba y ellos no oyeron la conversación y me dicen, "mira, nosotros somos de los mismos que te saludaron 
allá en Tennessee, en EEUU. Ya sabes quiénes somos". Y me dijeron, "no tenemos ningún asunto, sólo venimos a hacernos presentes, a saludarte, nada más. No hay nada, ningún asunto contra ti, ninguna nada". Yo ya ni les pude decir nada a mis polis.

Fuimos a visitar una cruz afuera, anduvimos por varios lugares y llegamos finalmente a un restaurant, donde nos invitaban personas de los organizadores de la Casa del Migrante. Una mesa pequeña. Y una de ellas, de las religiosas -yo les comenté lo que estaba pasando-y dice, "a ver, permíteme tu tablet", a uno de los que estaban ahí. Y empiezan a ver las fotos y en todo momento estuvieron atrás de mi. En todo momento. Mis guardias, ni caso. Pero estas dos personas estaba siempre atrás de mí, los de rojo. Ahí estaba uno de ellos, el comandante se había salido a fumar fuera del restaurante, y me dejó.

García-Caro: ¿Sus escoltas son de la policía municipal?

Solalinde:

No, son de la PGR, y son agentes de seguridad personal de la PGR. Así es que cuando yo me di cuenta de eso, dije, "este comandante ni siquiera se dio cuenta, y por salir a fumar, me dejó solo". Pudieron haberme matado ahí y ya, entonces yo pedí que lo cambiaran y lo cambiaron. Pero eso sucedió. De ahí ya nunca más me volvieron a contactar.

García-Caro: $\quad$ Esa escena que está describiendo, los escoltas se van a fumar y se quedan bien pegaditos los narcos, es 
una escena de película mexicana contemporánea, en realidad. En la que el estado hace la vista gorda. Parece como que hay dos estados. Yo creo que para mi esta es la pregunta más importante del México contemporáneo. Tengo un colega en la universidad en NY [Oswaldo Zavala] que dice que el narco no existe, que los carteles no existen, su libro se titula Los Carteles no existen, y acaba de salir en México. Según él los carteles no existen porque esto es en realidad una ficción que el estado ha montado, y en realidad todos son ramificaciones del estado, ni siquiera en descomposición, sino del estado. Yo no estoy tan seguro de esa tesis y me parece un poco descabellada, creo que el estado mexicano no tiene capacidad organizativa para que se produzca tal control. Sino más bien hay una descomposición en todos los niveles del estado, y casi una regionalización de poderes feudales, podríamos decir. Lo que queda es estado represor residual, en estados como Oaxaca, con gente como Ulises Ruiz antes, y ahora quizá un estado que regresa con MORENA. Si gana MORENA: ¿qué capacidad hay de recuperar un estado garantista? Son muchas preguntas juntas. Primero la descomposición, si es así; y segundo, de qué forma se puede regresar a un estado de garantías sociales y jurídicas.

Solalinde: $\quad$ Yo creo que sí es muy posible... el estado del daño, el deterioro del estado es muy grande. Porque prácticamente no hay ninguna institución del gobierno que no esté infiltrada por el crimen organizado. También 
es cierto que la corrupción es muy grande y que el estado se ha reducido ante el poder fáctico capitalista. Sin embargo, no todo está perdido todavía, todavía no está perdido todo. Y creo que México tiene todavía muchos recursos para impulsarse, para defenderse y para autorescatarse. Andrés Manuel sí pienso que pueda canalizar el hartazgo de la gente, pero también lo que va a hacer es lo del Pipila. Él va a tratar de dinamitar a la puerta, para que podamos entrar. Entrando, él no es el que tiene que decir cómo se van a hacer las cosas porque nadie quiere, ni él tampoco ser un mandatario presidencialista. Él no puede, no quiere ser una continuación de los mandatarios priistas. Entonces lo que va a hacer él es entrar, para que el pueblo gobierne, pero esto suena romántico si no hablamos de los cómos, de las organizaciones, de los tiempos. Él va a entrar, vamos a entrar nosotros y entonces vamos a tener que empezar a organizarnos.

¿Cuál es la esperanza de rescate? Primero, recuperar la soberanía interna. No estoy hablando de la emancipación económica, esa es otra cosa, es un rollote grandote. Pero ahorita de momento hacia nosotros, recuperar primero la consciencia de lo que somos, la identidad. Valorar nuestras raíces de los pueblos originarios indígenas, recuperar eso. Después, creer que podemos producir lo nuestro, que podemos salir un poquito de la esfera capitalista consumista, y empezar a consumir nuestros productos, lo que nosotros tengamos. Ahí está un principio de liberación muy interesante, el 
poder capitalista sobre México, se basa exactamente en la dependencia económica. Pero si nosotros dejamos de consumir cosas que podemos consumir en nuestro mercado, la influencia, la dependencia, va a disminuir. Nosotros tenemos tianguis, tenemos ropa, tenemos todo. Pero podemos también producir cosas que sí necesitamos, más limpias, más orgánicas más sanas, y que podamos inclusive, por qué no, pensar hasta una economía de trueque. No como un futuro, sino como estrategia de sobrevivencia y resistencia, mientras buscamos la forma de cómo incidir en el mercado internacional, de una manera menos dependiente. Pero eso lo dirán los economistas, "eso no". Pero hablamos un rescate de México, sí.

Tenemos una riqueza cultural muy grande, una riqueza espiritual todavía la tenemos, como para ir reduciendo la corrupción. Andrés Manuel sólamente es el pretexto, para que en realidad toda la gente capaz, porque estamos mucha gente muy capaz que podemos organizarnos desde abajo y construir un nuevo país. Yo no sé si han tenido ocasión de conocer Cherán. Ahora ya con la organización nueva que tiene, es un ejemplo padrísimo de liberación, de autonomía. La seguridad en manos del pueblo, ahí se llaman ronda, porque la gente misma hace turnos y se rola la seguridad y tiene seguridad. Y luego tiene un consejo mayor que es la autoridad. Ese consejo mayor está nombrado por las diferentes fogatas. En las esquinas cuando se ponen a platicar qué pasa, lo nombran. O sea, no puede haber nada más democrático 
que eso. Diego: el papel de las mujeres en Cherán Ahí las mujeres perdieron el miedo, hicieron que los hombres perdieran el miedo y ellos se administran. Además, una cosa muy inteligente: ellos no tuvieron que romper con el gobierno, con las instituciones. Si no que supieron cómo utilizarlas, cómo aprovecharlas para sus propósitos. Que les permite tomar distancia de los partidos, ahí no hay partidos políticos. Entonces ellos cuidan sus bosques, cuidan sus recursos. Acobo de esta cuando cumplieron 7 años.

García-Caro: ...fueron influenciados por el movimiento zapatista...

Solalinde:

...Un poco, pero es muy diferente. Mira, ellos han tomado distancia, son hermanos, pero han tomado distancia de la experiencia zapatista. Los zapatistas tuvieron que hacerlo así porque era una guerra. Ellos [Cherán] ya no tuvieron que hacer una guerra armada, tuvieron que hacer una guerra inteligente, estratégica. Mientras los zapatistas no quieren saber nada del gobierno, no reciben nada del gobierno. Acá no; acá dijeron sí a los usos y costumbres, y todo lo que sea del gobierno venga para acá, porque es nuestro, es del pueblo, pero no impide nuestra libertad. Entonces están usando al gobierno para el desarrollo y la consolidación de esa experiencia. Llevan 7 años de una nueva educación diferente, donde los niños y los jóvenes están entrando en razón de lo que está pasando, y tú pudiste ver ese día del aniversario: desfilaron 58 escuelas y cada escuela representa un cuadro distinto, donde se 
ve la conciencia de las niñas, de los niños. ¡Qué cosa más increíble! México puede lograr algo parecido, no como una receta de cocina, pero sí como una inspiración muy profunda de lo que sí podemos hacer.

Yo creo que México puede salir adelante y ser un país más igualitario. Si creo que vayamos a irle bajando a la oligarquía y no dejarles todo, porque estos son voraces porque son adictos. Un magnate es un adicto, un adicto al dinero. Hombre o mujer, no me interesa, ellos ya viven para tener y no hay nada más desequilibrado, más loco, más enfermizo que eso. Pensar que el sentido de la vida, el objetivo de la vida, es vivir para tener cosas que nunca te vas a llevar, que te van a quedar aquí. Yo he visto tantas cosas aquí en Estados Unidos que digo, "ipobres hombres!”. Ese 1\%, yo no estoy enojado con el 1\%; siento mucha compasión por ese $1 \%$, porque son las principales víctimas más cercanas del núcleo capitalista. Ellos están en el corazón del capitalismo y son los primeros que se los está fregando el capitalismo; ellos no viven, no van a vivir. Van a tener.

¿México puede rescatarse? Sí, se va a rescatar, pero necesitamos poco un poco un avance, un mínimo de confianza para la gente en sí mismos. Esperanza la tenemos, pero necesitamos confianza y ese día-porque vamos a ganar-ese día estamos ya discutiendo de muchas maneras en las redes, cómo lo vamos a festejar. Yo tengo ideas, como Solalinde, yo tengo ideas de cómo lo vamos a festejar anticipadamente. Yo tengo dos signos: primero voy a hacer un grupo de mujeres, 
"Mujeres por la Paz", y lo voy a hacer ya, y voy a invitar a mujeres de todos los partidos, de todas las religiones; a las esposas de los candidatos con la condición de que ellas vayan solamente como mujeres, y prepararlas para que entiendan que ahí son mujeres, sus títulos se quedan afuera, sus esposos y los partidos políticos y las creencias y los pedigrees, todos se queda afuera. Ahí nomás van a entrar como mujeres. $Y$ si es posible vamos a hacer un signo muy bonito esto.

Es toda una planeación, va a ser una planeación simbólica de las mujeres que se van a encontrar. Es un encuentro de las mujeres para ver ellas, independientemente de los vaivenes electoreros, que van a hacer por México. Ellas, las mujeres, solamente las mujeres, sólo mujeres. Entonces vamos a reunirnos en un lugar simbólico para que ellas digan. Y a partir de ahí generar un grupo de incidencia política, como autoridad moral. Muy importante que jalen a las demás mujeres y que orienten hacia dónde se quiere llegar con México. Cherán es el ejemplo; es un ejemplo que vivimos en Cherán.

Voy a convocar a jóvenes, un grupo de "Jóvenes por la Paz". Voy a convocar a los y las jóvenes para que hagamos un canto simplemente. Un canto, una canción. En algún lugar que no sé todavía, simbólico, y que cantemos "Sueño Imposible". Ese canto del Quijote." "Sueño Imposible", pues hacerlo y pensar que sí podemos soñar, que sí podemos cambiar al mundo. Soñar. Y luego, el día que ganemos, yo pienso invitar a toda la gente, a toda 
la gente a que con un signo de liberación, pero también de darle gracias a Dios, saquemos campanitas. Todos tienen campanas en sus casas, y la saquen a la calle y las empiecen a sonar. Chiquitas, grandotas, las que sean. Campanas de libertad de México, la independencia de México, como comienzo de una nueva Independencia, ahora económica. Pero eso lleva tiempo, no vamos a enfrentarnos ahorita con la macroeconomía pero nos vamos a concentrar en nosotros, consolidando nuestra identidad, nuestros valores, nuestros recursos y las dinámicas de una vida mejor. Yo pienso que se puede.

Contreras-Medrano: Tengo dos preguntas sobre lo que estás diciendo ahorita, sobre seguridad y sobre Andrés Manuel. Primero la de AMLO porque está más conectada. ¿Qué estrategias podemos seguir o qué estrategias MORENA debería replantear para atraer más votos? Los votos que eran de Marichuy, para atraer ese voto. ¿Qué estrategias se deberían de seguir para atraer sus votos hacia MORENA?

Solalinde:

Yo la única estrategia que he empleado con la gente, decirle, "mira, yo no soy de ningún partido- y de verdad, no soy de ningún partido, nunca he sido ni seré de ningún partido- pero soy una persona consciente y soy un agente de cambio, y me interesa que las cosas cambien. No pueden seguir como están". Toda mi influencia, mi prestigio, la estoy poniendo al servicio del cambio y el único que puede cambiar, es Andrés Manuel. Él no va hacer el cambio total, va a ser como la transición. Pero 
va a empezar entonces convencer a la gente. "Si no, qué opción me das, ¿Meade?”. ¿Puede cambiar el PRI? No. El PAN? El pan tuvo 12 años. ¿Por qué antes no y ahora sí? Tuvo toda la oportunidad y no lo hizo. Por qué lo vas a hacer ahora". Entonces decirle, "te caiga bien, te simpatice MORENA o no, ¿o si crees que Andrés Manuel tiene muchos defectos o muchos errores?". Decirles que sí. Pero es el único que puede sacar al PRI de los pinos y es el único que puede ayudarnos a empezar a cambiar. O lo tomas o lo dejas, pero si no estás con él, entonces de una vez ve votando por Meade, ve votando por el PAN, no hay de otra. No hay otro argumento, no hay de dónde. Ya faltan dos meses para las elecciones y no hay candidato más que los que ves; los demás son más de lo mismo, es para apuntalar el sistema capitalista, para condenar a México a la violencia y a la desigualdad. Entonces no hay más que poner todo nuestro peso por la única esperanza de cambio. Como dijo un atinado lector de la Jornada, él dijo, "a mi no me cae bien Andrés Manuel. A mí me interesa que cambie. Yo voy a votar por él, después ya que ganemos, ya me agarraré de las greñas con él”. Así lo puso en la sección de dinero, y se me hizo lógico. Sí habrá personas que no les convence Andrés Manuel. Seamos realistas, no tenemos el líder ideal; no existe, no hay el líder ideal, pero es lo que tenemos. O lo tomas o lo dejas. O lo tomas para que trates de cambiar, luchar por el cambio, o te resignas a seguir viviendo como estás viviendo hoy. Así de fácil es el planteamiento, no hay otra cosa, no hay opción. 
Contreras-Medrano: La ley de seguridad interior ¿qué crees que hay detrás?

Solalinde:

Pues lo que se ve, no hay detrás nada, todo está manifiesto. Está puesta ya, como lo que pasó en Honduras. Mira, en Honduras primero aprobaron una ley parecida de seguridad interior; luego viene Juan Orlando y consolida la dictadura descarada, apoyado por Estados Unidos. Y como protestas, viene la ley de seguridad interior aplicándola y la están aplicando con las fuerzas armadas, con el policía. Igual quieren hacer con México, pero México no es Honduras. México no es Honduras, cuidado porque si calculan mal, pueden perderlo todo. Ahorita todavía Andrés Manuel ha sido muy inteligente en decirle en broma, pero se lo dijo: "miren, sean inteligentes y salgan lo menos mal posible". Se los dijo, "no la hagan de tos, no hagan más problemas". Si la gente no los quiere, o qué van a disimular, ¿un fraude? Cuidado porque ni él va a poder contener a la gente. Yo mismo digo, estoy por la paz. Pero nadie puede decir que la gente no se vaya aventar, y en un último caso, a mí no me gustaría porque con la violencia perdemos todas y todos. Pero si orillan al pueblo a otro camino por la sobrevivencia, la violencia es legítima y entonces sí entraremos a ver cómo. Hasta ahorita estamos pensando en cosas pacíficas, en cosas de procesos estamos pensando, en procesos de cambio. Estratégicos y pacíficos. La oligarquía a través de sus voceros que son Videgaray y Peña y Made y el Nuño, se empeñan en aplastar al pueblo e imponerse, quién sabe. 
Contreras-Medrano: ¿Crees que hay intervencionismo de EEUU?

Solalinde:

Ciertamente sí. Estados Unidos va a querer siempre a los incondicionales, pero en un momento dado, si ven la de perder, ellos son pragmáticos. "A mí no me importa que seas tú o tú compadre. Quiero que me entreguen lo mío. Punto". No hay problema, porque además Andrés Manuel, como principio de estos procesos, no tiene la fuerza, no tiene la capacidad de enfrentar directamente, en un primer momento los poderes fácticos capitalistas. Pero va a empezar a poner cosas que van a buscar una mayor igualdad, un mayor desarrollo para la gente. Tiene que iniciar procesos porque si ahorita trata de hacer algo, ni el polvo lo va a apoyar a la hora de la hora, porque es un pueblo miedoso, un pueblo ignorante, que la verdad le falta mucho para leer. Pero si puede empezar procesos de concientización, de organizaciones; generar estructuras de información hacia la gente y de participación y decisión; de la gente hacia arriba. Eso sí puede hacer, cuadros de participación muy amplia de conciencia; campañas donde nos consolidamos como México, Yo pienso que se puede. Mira, Evo Morales él me enseñó mucho. En Bolivia yo vi muchas cosas muy bonitas; en Bolivia, por ejemplo, ¡no vi que odiaran a los pinches ricos! Hay un respeto para todos. Hay oligarquía, pero la gente está toda con Evo y con estos procesos. Ellos están solitos, ni caso les hacen, ya pueden hacer lo que quieran. Estados Unidos obviamente sí quiere la riqueza, 
el litio y todos los recursos que tiene Bolivia. Los quieren, pero no puede hacerlo porque están todos unidos en torno a Evo Morales, y Evo Morales ha encontrado la forma legal de cómo poder continuar al frente, porque sabe que ahorita hace falta todavía él.

Entonces sí podemos hacerlo. Podemos recuperar el agua, podemos recuperar el petróleo, lo podemos recuperar. Claro que sí.

García-Caro:

Se acaba, justo, de perder como final ya completo de la Revolución Mexicana. Recuerdo que cuando estuve [en México] en el 2013 al 2014, que justo estaba pasando la legislación con Peña Nieto, para poder privatizar por primera vez a Pemex, poder empezar a privatizar la industria petrolífera. Ese es justo el final del Cardenismo Revolucionario; es el último clavo que le faltaba al ataúd de la Revolución. Esto es uno de los principios básicos de soberanía, que es el de la propiedad comunal, de los productos minerales y de las reservas nacionales. Eso es de lo primero que habría que cambiar.

Solalinde:

Otra cosa que tiene que cambiar -y no me lo están preguntando- pero va a ser muy emocionante, es la iglesia: la jerarquía. La iglesia ha llegado tarde a todos los eventos de la historia de México. En la independencia estuvo del lado de los conquistadores y de los colonizadores. Estuvo del lado de ellos. En la Reforma, estuvo de lado de los conservadores, de la monarquía. 
García-Caro: ...aunque fue un cura, como Solalinde, el que empezó la independencia...

Solalinde: ...en la Reforma, la iglesia estuvo en contra de los liberales. En la revolución igual. En la Guerra Cristera, ahí se le salió a la jerarquía, los curas y el pueblo laico. Ellos solitos. La jerarquía no tuvo nada, más que al final en los Arreglos: al final, como la iglesia es muy de obediencia, impusieron los Arreglos. Hoy vuelve a lo mismo la Iglesia: el pueblo otra vez vuelve a enfrentarse a la oligarquía, a la tiranía -porque es un gobierno tiránico el de Peña Nieto. Entonces ahora lo que toca es unirnos. ¿De qué lado va a estar la Iglesia? si la Iglesia -la jerarquía- vuelve a cometer el mismo error y no apoyar al pueblo, se va a quedar sola. Y otra vez la van a seguir marginando; otra vez porque la iglesia somos los bautizados, no la jerarquía nada más. Nosotros somos los que estamos haciendo la revolución.

García-Caro: $\quad$ Pero no me ha respondido sobre los recursos naturales y la soberanía...

Solalinde:

Los recursos naturales tendrán que pasar otra vez al pueblo. Yo no me opongo a la privatización de lo que sea privatizable. Pero, así como que quitarle todo y pasar en manos de la propiedad privada, es riesgoso. Porque estamos viendo que, en Bolivia, resulta ventajoso no dejar que privaticen el agua, los recursos estratégicos 
que sirvan para un mayor desarrollo de la mayoría. $Y$ finalmente, ¿qué hemos ganado con la reforma energética? ¿Qué hemos ganado con haberle dado ganancias a las compañías extranjeras? Nada. El dinero de la gasolina y el petróleo se va para ellos. ¿Quiénes ganamos con eso? Ellos se lleva las ganancias, no nosotros. Entonces tenemos que luchar por los recursos. Reorganizar México. Reorganizar México y la economía también. Yo me imagino que, en lugar de ir a comprar a lugares grandes, moles grandes, centros comerciales y eso, ir por ejemplo, a los tianguis: los tianguis son padrísimos, no hay cosas más hermosas. Te encuentras de todo ahí: tu ropita, tu guayabera, cosas que tenemos nosotros. ¡Hasta artesanías! Todo lo que hay, de colores tan bonitos que tenemos. Hay que comprarlo ahí, ir al mercado. Tantas cosas que son nuestras y que no tienes ni siquiera que pelearte con las transnacionales. Simplemente no les compre, y ya. Compra mejor acá.

Bajarle al consumismo. El gobierno tiene también que reducir sus gastos. Hay una palabra muy bonita que Andrés Manuel usa mucho: la austeridad. La austeridad no es ser muertos de hambre. La austeridad es aprender a construir, ser consumista de lo necesario, y ya. Y vivir libre, libre. ¿Aunque haya mucho? ¡Qué bueno que hay mucho! Yo lo comparó con un buffet. En un buffet tienes muchas opciones, y si es un buen buffet, entrada-salida, de postres, de todo. ¿Pero a poco te vas a comer todo porque hay mucho? Una cosa es, que bueno que haya. Pero tú no eres bodega, tú no eres almacén; tú vas a 
tomar lo que puedas, en la cantidad que tu cuerpo lo pueda recibir. Lo demás no, porque lo dañas. ¿Hay mucho? Pues qué bueno, se queda. Pero ser libre de eso, aprender a ser libre de las cosas y no depender del consumismo. Todo eso lo podemos hacer nosotros.

Contreras-Medrano: Yo sí tengo una pregunta en cuanto a la Iglesia: no es éticamente correcto decirle a la gente por quién votar, pero sabemos que la Iglesia Católica, los Padres, se han vuelto agentes políticos, como es tu caso. Pero también tenemos un montón de Padres insistiendo en votar por el PAN, por el PRI. ¿Qué hacer para concientizar éticamente a los Padres, a la Iglesia?

Solalinde:

Está muy difícil. Mira, es tanto como decirme que fuera a Guerrero para platicar con Calleja o con el Virrey o con el Arzobispo de entonces, y convencerlos de la independencia. Pues no, ¿verdad? Porque estos obispos de ahora, aunque son buenas personas, son privilegiados. Viven arriba. No tienen la experiencia del hambre, no tienen la experiencia de ser comunes con la gente de a pie. Es muy difícil, ellos se van a abstener. Mira, si yo te enseñara las notas que yo le mando al vocero del episcopado. Yo le digo, "está la situación así". No va a decir nada a la Iglesia, como vocero, no va a decir nada. Yo lo empujo a que diga, pero no dice nada. Callado. Yo creo que la jerarquía católica no va a hacer gran cosa. Pero aquí le pueblo, gracias a Dios, ya está creciendo un poco. Ya está madurando, ya no va a ser 
tan niño para pedirle permiso al obispo o al párroco, para hacer lo que tiene que hacer. ¿Si me entiendes? Yo como sacerdote, soy también un ejemplo de ello. Yo no voy a pedir permiso a ningún obispo, a ningún hermano sacerdote, para cumplir con México. Lo que yo tenga que hacer, ya es responsabilidad mía, nadie me puede decir nada. ¿Que ellos no lo hagan? Es su problema, yo lo voy a hacer. Lo que sea. Lo que toque. En el momento que sea.

Contreras-Medrano: ¿Cuál opinas que debería ser la agenda migratoria que debería seguir Andrés Manuel?

Solalinde:

Lo primero que tiene que hacer, es separar la política del aspecto administrativo de la seguridad. Es lo primero que tiene que hacer, de hecho, la ley si lo contempla, la ley del 2011, la ley migratoria del 24 de febrero 2011. Lo contempla, la migración es un asunto administrativo y de hecho el carácter del Instituto Nacional de Migración, es administrativo. Porque no es policiaco, porque no tiene armas, porque no tiene por qué hacer funciones del Ministerio Público, ni nada de eso. Pero en la práctica sí lo hace, porque la ley es una cosa, pero el reglamento, la ley secundaria que te dice con qué vas a aplicar la ley y cómo la vas a aplicar. Ahí es donde metieron trampa y también en los lineamientos. Esas dos cosas. Entonces ahí sí de facto meten a migración como si fuera un cuerpo más de seguridad. Yo digo eso, separar y dejarle a migración solamente, su aspecto migratorio administrativo. Porque 
si junto las dos cosas, es fuente de violación de Derechos Humanos. Pero también corrupción, porque ahí es donde se corrompen agentes federales de migración. Yo lo que haría sería revitalizar e implementar y seguir el programa especial de migración, el PEM. El Programa Especial de Migración lo hizo un gran hombre, Omar de la Torre, un gran defensor de Derechos Humanos que era funcionario de gobernación en ese momento, y lo hizo con muchas organizaciones de la sociedad civil durante dos años. Durante dos años lo hicimos, cuando lo terminamos, Felipe Calderón no alcanzó a publicarlo y le toca a Peña Nieto, y lo publica en el Diario Oficial. Lo pone con carácter de obligatorio, además pone a dos secretarías para que le den seguimiento: la Secretaría de la Función Pública y Gobernación. Lo pone como obligatorio y hace que firmen todos los secretarios de estado. Cuando este cuate se da cuenta de que era un compromiso hacia los Derechos Humanos, lo hace un lado y lo olvida. Entonces yo le reclamo y le digo, "por qué, si es trabajo de nosotros". No hizo caso, lo hizo a un lado. ¡Ah! pero el año pasado, en Suiza, lo presumió y lo presentó como un logro, cuando él, en realidad, lo había hecho a un lado. Entonces el PEM debe volver actualizarse debe de repetirse para que se siga. $Y$ otra cosa, debe de respetarse todas las recomendaciones, pero también las reiteraciones de la ONU respecto a la política pública migratoria de México; debe de replantearse eso y cumplir con esos compromisos.

Otra cosa importantísima. No tenemos ni que 
pelearnos con Estados Unidos, ni siquiera tenemos que pelearnos con él. Hay cosas que no tenemos por qué pedirle permiso a él. Por ejemplo, si de veras queremos que ya no pase tanto migrante, el muro no va a servir para nada, ni tampoco el Instituto Nacional de Migración, porque se corrompen. Se hace negocio con ellos nada más, le ven la cara de tonto a los norteamericanos. Hay que hacer un programa de desarrollo integral en Centroamérica, México y Estados Unidos. A Estados Unidos le conviene invertir ahí, porque esta es la verdadera solución. Yo esto lo traté personalmente en Centroamérica con autoridades de Centroamérica y de México, el departamento de estado, y con el embajador Antonio Wayne y dijeron, "nos gusta este plan, estamos dispuestos a hacerlo". Hay una palabra que ellos dicen, "estamos listos; I am ready; We are ready". Las condiciones que ponían era que México fuera el líder, que hubiera transparencia en esto y que sí se hiciera algo corresponsablemente. Nunca se hizo porque México no tuvo voluntad política, n no le interesó. Pero eso se tiene que hacer ahora con la corresponsabilidad de los países expulsores de Centroamérica, se tiene que hacer. Todo eso se tienen que revisar: reunir a todas las casas del migrante, reunir a más de 90 organizaciones de la sociedad civil que tenemos que ver con migrantes, y entre todas y todos generar esas políticas públicas transparentes, que todo mundo sepa. $Y$ decirle a EEUU, "se va a hacer así". Y ya. El recurso que da EEUU mediante el Plan Mérida, no tiene que ver nada con 
Derechos Humanos. Porque, aunque ellos dicen que sí condicionan a Derechos Humanos, en la práctica no se hace nada. Nosotros queremos que sí se diga y que sí se haga.

Otra cosa. Nosotros queremos que Europa aplique la cláusula de respeto a los Derechos Humanos a los tratados comerciales entre Europa y Mexico. Que lo aplique, porque no lo ha querido hacer. Pero el mismo gobierno puede aplicarlo. Ahorita estaría AMLO, pero después no. Queremos que los Derechos Humanos no sea algo coyuntural, sino algo estructural y permanente. Todo eso hay que hacer.

García-Caro:

Hay modelos de saqueo y de explotación a los migrantes que son tan espectaculares, quizá todavía no se visualiza lo suficiente. Por ejemplo, en Estados Unidos los centros de detención y procesamiento de los migrantes, son centros que están privatizados; son concesiones del Estado Federal a instituciones privadas, y que los retienen durante seis meses y por cada migrante cobran, estas instituciones, $\$ 75$ al día o algo así. Con lo cual, de nuevo, sería una forma de pagar piso. Casi como lo que está ocurriendo en México, pero hecho al estilo americano. Es decir, con grandes centros, todo muy regulado, informatizado y moderno. Porque para ellos sería preferible que ustedes los mexicanos hubieran hecho unos centros de detención privatizados, y que hubieran hecho un negocio. En lugar de que lo hubieran hecho de manera informal, con narcos. Ese es el modelo 
americano. Ustedes hubieran llevado a cabo un modelo americano.

Contreras-Medrano: Ese es el verdadero problema de la migración. El problema migratorio es que no hay una clara separación entre la labor de seguridad de la administración. El problema no es que la gente migre; el problema es que los criminalizamos, los detenemos. Ese es el problema.

Solalinde:

La nueva política migratoria tiene que reprimir inmediatamente los centros de detención. Los centros migratorios deben desaparecer inmediatamente. Ningún agente de migración, ningún policía, debe de perseguir a ningún migrante. Se le tiene que reconocer como regular administrativo, porque la ley es muy clara. Dice ahí que es regular administrativo. $Y$ a nadie por una falla administrativa, se le va a meter a la cárcel o se le persigue ni se le golpea. Pero ellos sí, porque es una gran contradicción, y es lo que le dice el comité de la ONU a México, el 13 de septiembre del año pasado, como respuesta al Tercer Examen Periódico Universal. El EPU. Las detenciones migratorias se tienen que quitar; si los migrantes quién ir a tocar las puertas de EEUU, "son bienvenidos, pásenle. Nadie los va a detener”. ¡Claro! Es su problema, no es problema nuestro. Es problema de EEUU si los deja entrar, si se le meten, es su problema, pero México no tiene ya por qué ser policía migratorio de EEUU. Eso es vergonzoso. Quiero ser honesto. EEUU nunca le dijo a México, "Viola sus derechos. Abusa”. Les 
ha puesto seis sanciones económicas a México, por abuso de autoridad, por atropellos a los derechos humanos de las personas migrantes. Por lo menos seis sanciones económicas.

\section{Notas}

1 Se refiere a la canción "Sueño imposible", traducción de "Impossible Dream" de Joe Darion y Mitch Leigh para el musical de Broadway Man of La Mancha (1965). 